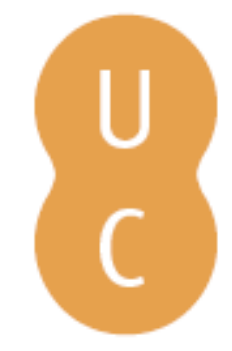

\title{
pommalina
}

\section{Foraminíferos atuais do litoral de Benguela (Angola): caracterização taxonómica e implicações biogeográficas}
Autor(es):
Canales, M. L.; Henriques, M. H.; Mbadu, E.
Publicado por: Centro de Estudos Clássicos e Humanísticos da Universidade de
URL persistente:
Coimbra
DOI:
URI:http://hdl.handle.net/10316.2/31423
DOI:http://dx.doi.org/10.14195/978-989-26-0534-0_19
Accessed : $\quad$ 26-Apr-2023 09:57:39

A navegação consulta e descarregamento dos títulos inseridos nas Bibliotecas Digitais UC Digitalis, UC Pombalina e UC Impactum, pressupõem a aceitação plena e sem reservas dos Termos e Condições de Uso destas Bibliotecas Digitais, disponíveis em https://digitalis.uc.pt/pt-pt/termos.

Conforme exposto nos referidos Termos e Condições de Uso, o descarregamento de títulos de acesso restrito requer uma licença válida de autorização devendo o utilizador aceder ao(s) documento(s) a partir de um endereço de IP da instituição detentora da supramencionada licença.

Ao utilizador é apenas permitido o descarregamento para uso pessoal, pelo que o emprego do(s) título(s) descarregado(s) para outro fim, designadamente comercial, carece de autorização do respetivo autor ou editor da obra.

Na medida em que todas as obras da UC Digitalis se encontram protegidas pelo Código do Direito de Autor e Direitos Conexos e demais legislação aplicável, toda a cópia, parcial ou total, deste documento, nos casos em que é legalmente admitida, deverá conter ou fazer-se acompanhar por este aviso.

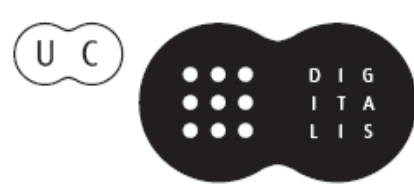





\title{
FORAMINÍFEROS ATUAIS DO LITORAL DE BENGUELA (ANGOLA): CARACTERIZAÇÁO TAXONÓMICA E IMPLICAÇÓES BIOGEOGRÁFICAS
}

\author{
RECENT FORAMINIFERA FROM THE BENGUELA \\ COAST (ANGOLA): TAXONOMIC CHARACTERIZATION \\ AND BIOGEOGRAPHIC IMPLICATIONS
}

M. L. Canales ${ }^{1}$, M. H. Henriques ${ }^{2} \&$ E. Mbadu $^{3}$

\begin{abstract}
Resumo - No presente trabalho apresenta-se a caracterização taxonómica das associaçôes de foraminíferos bentónicos e planctónicos reconhecidas em sedimentos atuais do litoral de Benguela (Angola) e discute-se o seu valor do ponto de vista biogeográfico. Este estudo assenta em cinco amostras recolhidas em cinco locais situados entre o Cuio (a sul) e o Lobito (a norte), e, a partir delas, obteve-se um total de 424 exemplares.

Do ponto de vista taxonómico, as associaçôes são constituídas por formas bentónicas e planctónicas, sendo as primeiras dominantes. Reconheceram-se 6 subordens, 22 famílias e 32 géneros, sendo muito abundantes nas associaçóes os representantes da Subordem Rotaliina, das Famílias Uvigerinidae, Rotaliidae e Elphidiidae e dos Géneros Uvigerina, Ammonia e Elphidium. Seguem-se, quanto à abundância relativa, os representantes das subordens Lagenina, Globigerinina e Miliolina, considerando-se Robertinina e Textulariina como minoritárias.

A presença de representantes de determinados táxones, bem como o reconhecimento de certas características morfológicas das carapaças dos representantes da Subordem Globigerinina, permitem reconhecer bioprovíncias nos oceanos atuais. Neste caso, a análise das carapaças planctónicas registadas no material estudado permitiu reconhecer a presença dos táxones que se distribuem na bioprovíncia Subtropical, bem como a influência da Corrente Fria de Benguela, naquela zona do litoral de Angola.
\end{abstract}

\footnotetext{
1 Departamento de Paleontologia, Facultad de Ciencias Geológicas, Universidad Complutense de Madrid, España; mcanales@geo.ucm.es

2 Departamento de Ciências da Terra e Centro de Geociências; Faculdade de Ciências e Tecnologia da Universidade de Coimbra; 3000-272 Coimbra, Portugal; hhenriq@dct.uc.pt

${ }^{3}$ Escola de Formação de Professores; Rua 10 de Fevereiro, Benguela, Angola; emilianambadu@yahoo.com
} 
Palavras-chave - Foraminíferos atuais; Benguela; Angola; Taxonomia; Biogeografia

Abstract - In this work the taxonomic characterization of the benthic and planktonic foraminifera assemblages recorded in Recent sediments along the Benguela coast (Angola) is presented, and its implications from a biogeographic point of view are discussed. The study is based on five samples collected in five localities between Cuio (southern Benguela) and Lobito (northern Benguela), which have provided a total of 424 specimens.

From a taxonomic point of view, 6 suborders, 22 families and 32 genera were recognized, the most abundant belonging to the Suborder Rotaliina, Families Uvigerinidae, Rotaliidae and Elphidiidae, and Genera Uvigerina, Ammonia and Elphidium. They are followed by representatives of the suborders Lagenina, Globigerinina and Miliolina, being Textulariina and Robertinina, considered as minoritary.

The presence of representatives of certain taxa, and the recognition of certain morphological characteristics of the shells of representatives of the Suborder Globigerinina, allow the recognition of bioprovinces in the present day oceans. In this case, the analysis of planktonic shells recorded in the studied material allow us to recognize the presence of taxa characteristic in the Sub-tropical bioprovince, as well as the influence of the Benguela Cold Current, in that part of the Angola coast.

\section{Keywords - Recent Foraminifera; Benguela; Angola; Taxonomy; Biogeography}

\section{1 - Introdução}

O presente trabalho refere-se a uma investigação realizada no âmbito do Mestrado em Geociências da Universidade de Coimbra, centrada no estudo de associaçóes de foraminíferos atuais (bentónicos e planctónicos), que se obtiveram a partir de cinco amostras recolhidas no litoral da província angolana de Benguela (MBADU, 2011), entre as localidades de Cuio e Lobito (Fig. 1). Com ele, pretende-se alargar o conhecimento acerca das associaçóes de foraminíferos atuais que se podem encontrar no litoral de Angola, através do estudo taxonómico dos espécimes nelas reconhecidos, bem como contribuir para a caracterização das províncias biogeográficas atuais, definidas com base na ocorrência de foraminíferos planctónicos.

\section{2 - Materiais e métodos}

Foram recolhidas 5 amostras de sedimentos de praia, com aproximadamente 500 gramas de peso cada uma, cujas coordenadas estão representadas na Tabela 1.

No laboratório, procedeu-se à descrição macroscópica das amostras recolhidas e, posteriormente, retiraram-se 150 gramas de cada uma, que foram separadas em quatro fraçóes $(>0,500 \mathrm{~mm},>0,250 \mathrm{~mm},>0,125 \mathrm{~mm},>0,063 \mathrm{~mm})$. Cada uma destas fraçóes foi pesada e arquivada, para posterior triagem, que foi realizada através da utilização de uma lupa binocular, modelo BMS-79457.

Os foraminíferos obtidos foram classificados, a nível de género, segundo a classificação de LOEBLICH \& TAPPAN (1988), e alguns dos táxones mais representativos foram fotografados ao microscópio eletrónico de varrimento, modelo JEOL 6400, no Centro Nacional de Microscopía Electrónica, situado na Universidade Complutense de 
Madrid (Espanha). O material estudado está arquivado no Laboratório de Paleontologia da Faculdade de Ciências e Tecnologia da Universidade de Coimbra (Portugal).

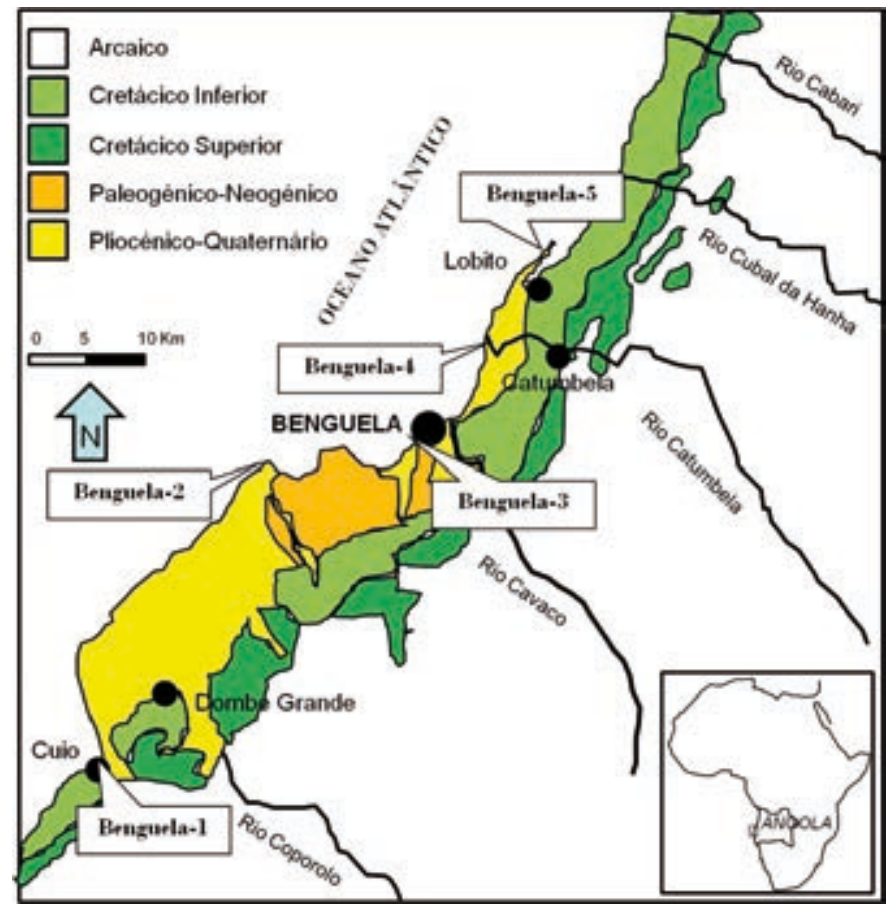

Fig. 1 - Localização da área de estudo e dos pontos de amostragem, utilizando a cartografia geológica de TAVARES et al. (2007).

Tabela 1 - Coordenadas geográficas dos locais amostrados para a realização do presente trabalho.

\begin{tabular}{cccc} 
Amostra & Localizaçáo & Latitude & Longitude \\
\hline Benguela 1 & Cuio - Dombe Grande & $12^{\circ} 58^{\prime} 29,45^{\prime \prime} \mathrm{S}$ & $13^{\circ} 59^{\prime} 06,11^{\prime \prime} \mathrm{E}$ \\
\hline Benguela 2 & Baia Farta - Dungo & $12^{\circ} 40^{\prime} 20,16^{\prime \prime} \mathrm{S}$ & $13^{\circ} 08^{\prime} 13,48^{\prime} \mathrm{E}$ \\
\hline Benguela 3 & S. António - Benguela & $12^{\circ} 37^{\prime} 06,78^{\prime \prime} \mathrm{S}$ & $13^{\circ} 20^{\prime} 59,72^{\prime \prime} \mathrm{E}$ \\
\hline Benguela 4 & Praia Bebé - Catumbela & $12^{\circ} 24^{\prime} 34,72^{\prime \prime} \mathrm{S}$ & $13^{\circ} 29^{\prime} 53,39^{\prime \prime} \mathrm{E}$ \\
\hline Benguela 5 & Restinga - Lobito & $12^{\circ} 18^{\prime} 55,86^{\prime \prime} \mathrm{S}$ & $13^{\circ} 35^{\prime} 00,89^{\prime \prime} \mathrm{E}$ \\
\hline
\end{tabular}

\section{3 - Resultados}

Na presente secção apresenta-se o índice taxonómico dos foraminíferos identificados e o número de exemplares obtidos nas amostras recolhidas no litoral de Benguela (Angola). Reconheceram-se 6 subordens, 22 famílias e 32 géneros, estando figurados os mais representativos (Estampa, Figs. 1-31). Discutem-se, igualmente, as implicaçóes biogeográficas derivadas da presença dos táxones planctónicos registados nas amostras estudadas. 


\section{1 - Índice taxonómico}

Phyllum Sarcodina Schmarda, 1871

Classe Rhyzopodea Von Siebold, 1845

Ordem Foraminiferida Eichwald, 1830

Subordem Textulariina Delage \& Hérouard, 1896

Superfamília Hormosinacea Haeckel, 1894

Família Hormosinidae Haeckel, 1894

Subfamília Reophacinae Cushman, 1910

Género Reophax de Montfort, 1808 (Estampa, Fig. 1)

Superfamília Textulariacea Ehrenberg, 1838

Família Eggerellidae Cushman, 1937

Subfamília Dorothiinae Balakhmatova, 1972

Género Dorothia Plummer, 1931 (Estampa, Fig. 2)

Subfamília Eggerellinae Cushman, 1937

Género Karreriella Cushman, 1933 (Estampa, Fig. 3)

1 exemplar

Subordem Miliolina Delage \& Hérouard, 1896

Superfamília Miliolacea Ehrenberg, 1839

Família Hauerinidae Schwager, 1876

Subfamília Hauerininae Schwager, 1876

Género Quinqueloculina d'Orbigny, 1876 (Estampa, Fig. 4)

17 exemplares

Subordem Lagenina Delage \& Hérouard, 1896

Superfamília Nodosariacea Ehrenberg, 1838

Família Nodosariidae Ehrenberg, 1838

Subfamília Nodosariinae Ehrenberg, 1838

Género Mucronina Ehrenberg, 1839 (Estampa, Fig. 5)

2 exemplares

Género Nodosaria Lamarck, 1812 (Estampa, Fig. 6)

8 exemplares

Género Pseudonodosaria Boomgaart, 1949 (Estampa, Fig. 7)

6 exemplares

Família Vaginulinidae Reuss, 1860

Subfamília Lenticulininae Chapman, Parr \& Collins, 1934

Género Cribrorobulina Thalmann, 1947 (Estampa, Fig. 8)

Género Lenticulina Lamarck, 1804 (Estampa, Fig. 9)

Família Polymorphinidae d’Orbigny, 1839

Subfamília Polymorphininae d'Orbigny, 1839

Género Globulina d'Orbigny, 1839 (Estampa, Fig. 10)

Subordem Robertinina Loeblich \& Tappan, 1984

Superfamília Robertinacea Reuss, 1850

Família Robertinidae Reuss, 1850

Subfamília Alliatininae MsGowran, 1966

Género Robertina d'Orbigny, 1846 (Estampa, Fig. 11)

Subordem Globigerinina Delage \& Hérouard, 1896

Superfamília Globorotaliacea Cushman, 1927

Família Catapsydracidae Bolli, Loeblich \& Tappan, 1957

Género Globoquadrina Finlay, 1947

Superfamília Globigerinacea Carpenter, Parker \& Jones, 1860

Família Globigerinidae Carpenter, Parker \& Jones, 1860

Subfamília Globigerininae Carpenter, Parker \& Jones, 1860

Género Globigerina d'Orbigny, 1826 (Estampa, Figs. 12-13)

Género Globigerinella Cushman, 1927 (Estampa, Fig. 14)

Género Globigerinoides Cushman, 1927 (Estampa, Fig. 15)

Subfamília Orbulininae Schultze, 1854

Género Orbulina d'Orbigny, 1839 (Estampa, Fig. 16)

2 exemplares

29 exemplares

2 exemplares

4 exemplares

1 exemplar

14 exemplares

6 exemplares

5 exemplares

1 exemplar 
Subordem Rotaliina Delage \& Hérouard, 1896

Superfamília Bolivinacea Glaessner, 1937

Família Buliminidae Jones, 1875

Género Bulimina d'Orbigny, 1826 (Estampa, Fig. 17)

Família Bolivinidae Glaessner, 1937

Género Bolivina d'Orbigny, 1839 (Estampa, Fig. 18) 14 exemplares

Género Brizalina Costa, 1856 (Estampa, Fig. 19) 13 exemplares

Superfamília Buliminacea Jones, 1875

Família Uvigerinidae Haeckel, 1894

Subfamília Uvigerininae Haeckel, 1894

Género Uvigerina d'Orbigny, 1826 (Estampa, Fig. 20)

Subfamília Angulogerininae Galloway, 1933

Género Trifarina Cushman, 1923 (Estampa, Fig. 21)

Superfamília Discorbacea Ehrenberg, 1838

Família Bagginidae Cushman, 1927

Subfamília Baggininae Cushman, 1927

Género Cancris de Montfort, 1808

Família Sphaeroidinidae Cushman, 1927

Género Sphaeroidina d'Orbigny, 1826 (Estampa, Fig. 22)

Superfamília Glabratellacea Loeblich \& Tappan, 1964

Família Parrelloididae Hofker, 1956

Género Cibicidoides Thalmann, 1939 (Estampa, Fig. 23)

Superfamília Planorbulinacea Schwager, 1877

Família Planulinidae Bermúdez, 1952

Género Planulina d'Orbigny, 1826 (Estampa, Figs. 24) 19 exemplares

Família Cibicididae Cushman, 1927

Subfamília Cibicidinae Cushman, 1927

Género Cibicides de Montfort, 1808

Superfamília Nonionacea Schultze, 1854

Família Nonionidae Schultze, 1854

Subfamília Nonioninae Schultze, 1854

Género Nonion de Montfort, 1808 (Estampa, Fig. 25)

Subfamília Pulleniinae Schwager, 1877

Género Melonis de Montfort, 1808 (Estampa, Fig. 26)

Superfamília Chilostomellacea Brady, 1881

Família Heterolepidae González-Donoso, 1969

Género Heterolepa Franzenau, 1884 (Estampa, Fig. 27)

Superfamília Rotaliacea Ehrenberg, 1839

Família Rotaliidae Ehrenberg, 1839

Subfamília Ammoniinae Saidova, 1981

Género Ammonia Brünnich, 1772 (Estampa, Figs. 28-29) 68 exemplares

Família Calcarinidae Schwager, 1876

Género Calcarina d'Orbigny, 1826 (Estampa, Fig. 30)

Família Elphidiidae Galloway, 1933

Subfamília Elphidiinae Galloway, 1933

Género Elphidium de Montfort, 1808 (Estampa, Fig. 31)

47 exemplares

3 exemplares

1 exemplar

9 exemplares

25 exemplares

1 exemplar

16 exemplares

1 exemplar

14 exemplares

1 exemplar

67 exemplares

Com um total de 314 exemplares, a subordem mais abundante, no conjunto das amostras estudadas, é Rotaliina. Segue-se a Subordem Lagenina, com 59 exemplares, e a Subordem Globigerinina, com 27 exemplares. Da Subordem Miliolina só foram obtidos 17 exemplares, e as subordens Robertinina e Textulariina podem ser consideradas minoritárias, com 4 e 3 exemplares respetivamente. 


\section{2 - Implicações biogeográficas}

A temperatura da água influencia, por um lado, a composição das populaçôes de foraminíferos planctónicos, cuja distribuição, em função deste fator ecológico, é a base do estabelecimento de províncias biogeográficas nos oceanos atuais (Fig. 2). Além disso, a temperatura da água também condiciona o sentido de enrolamento das carapaças de alguns géneros de foraminíferos planctónicos, sendo levógiras em latitudes altas, e dextrógiras em latitudes mais baixas (AMSTRONG \& BRASIER, 2005).

A área de estudo situa-se na bioprovíncia Subtropical (Fig. 2), mas é afetada diretamente pela Corrente Fria de Benguela, que movimenta águas frias do sul para norte, ao longo da costa africana. Nas amostras estudadas identificaram-se géneros que se desenvolvem nesta bioprovíncia (p.e., Globigerina, Globigerinella, Globigerinoides e Orbulina), mas é de salientar que algumas das carapaças destes géneros apresentam carapaças levógiras, típicas de águas frias (Estampa, Figs. 13, 14 e 15). Além disso, identificou-se o género Globoquadrina, que atinge a sua máxima abundância na bioprovíncia Polar (HEMLEBEN et al., 1989). Assim, as associaçôes registadas no litoral de Benguela são dominadas por táxones característicos da bioprovíncia correspondente à latitude (Subtropical), mas registou-se a presença de algumas carapaças, características de latitudes mais altas, que terão sido transportadas para norte pela Corrente Fria de Benguela.

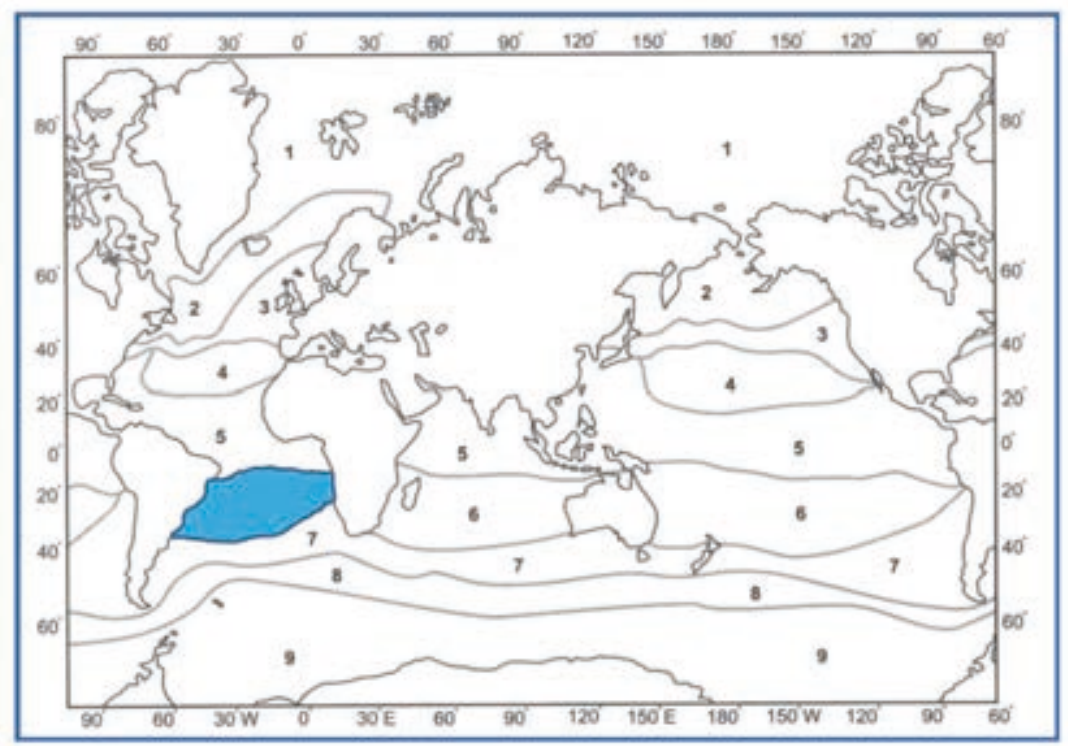

Fig. 2 - Províncias biogeográficas atuais de foraminíferos planctónicos. 1. Ártica; 2. Subártica;

3. De transição; 4. Subtropical; 5. Tropical; 6. Subtropical; 7. De transição; 8. Subantártica;

9. Antártica (retirado de AMSTRONG \& BRASIER, 2005, com base em dados de

BELYAEVA, 1963). A mancha a azul assinala a bioprovíncia Subtropical,

na qual se inserem as amostras estudadas no presente trabalho. 


\section{4 - Conclusóes}

As associaçóes de foraminíferos do litoral de Benguela estudadas no presente trabalho são pouco abundantes, mas muito diversas. São constituídas por formas bentónicas e planctónicas, sendo as primeiras dominantes. Identificaram-se 6 subordens: a mais abundante é Rotaliina; seguem-se Lagenina, Globigerinina e Miliolina, considerando-se Robertinina e Textulariina como minoritárias.

A análise das carapaças planctónicas registadas no material estudado permitiu reconhecer a presença de táxones comuns na bioprovíncia Subtropical, bem como a influência da Corrente Fria de Benguela, naquela zona do litoral de Angola.

Agradecimentos - Este trabalho insere-no no âmbito das atividades dos projetos CGL2011-23947 - "Taxones Submediterráneos y Cambios Paleobiogeográficos en el Jurásico Medio de la Cordillera Ibérica” e CGL2008-03112 - “Crisis bióticas mesozoicas, entre el Triásico Superior y el Jurásico Medio, en el sistema de plataformas ibéricas. Eventos de extinción-renovación y cambios climáticos asociados”, do Ministerio de Educación y Ciencia (Espanha) e o trabalho de laboratório beneficiou do apoio do Consórcio Petrobras-Galp-Partex.

\section{Referências Bibliográficas}

AMSTRONG, H. \& BRASIER, M. D. (2005) - Microfossils. Blackwell Publ., 2nd ed., 296 p.

BELYAEVA, N. V. (1963) - The distribution of planktonic foraminifers over the Indian Ocean bottom. Voprosi Mikropaleontologii, 7, p. 209-222.

HEMlEBEN, Ch., SPINDLER, M. \& ANDERSON, O. R. (1989) - Modern Planktonic Foraminifera. Springer-Verlag, $363 \mathrm{p}$.

LOEBLICH, A. R. \& TAPPAN, H. (1988) - Foraminifera genera and their classification. Van Nostrand Reinhold Company, New York, 2, 970 p.

MBADU, E. (2011) "Foraminíferos actuais do litoral de Benguela (Angola)“. Tese de Mestrado, Departamento de Ciências da Terra, Faculdade de Ciências e Tecnologia da Universidade de Coimbra: 84p. (não publicado).

TAVARES, T. S., MEISTER, C., DUARTE-MORAIS, M. L. \& DAVID, B. (2007) - Albian ammonites of the Benguela Basin (Angola): a biostratigraphic Framework. South African Journal of Geology, 110, p. 137-156. 


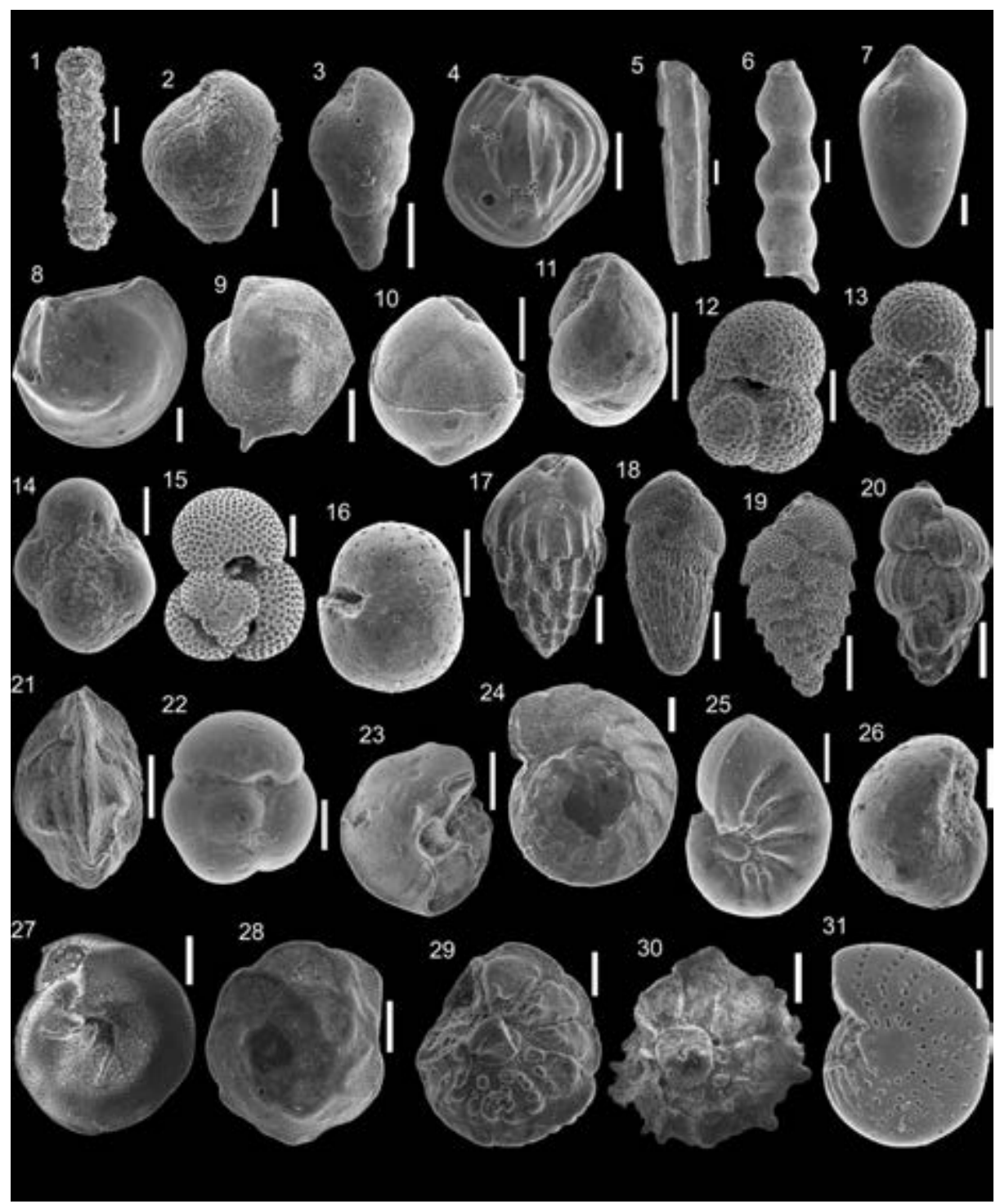


Legenda da estampa (todas as escalas gráficas representam 100 $\mu$ ): 1. Reophax de Montfort, 1808 (BE-1-51); 2. Dorothia Plummer, 1931 (BE-3-16); 3. Karreriella Cushman, 1933 (BE-3-8); 4. Quinqueloculina d'Orbigny, 1876 (BE-3-25); 5. Mucronina Ehrenberg, 1839 (BE-3-38); 6. Nodosaria Lamarck, 1812 (BE-3-44); 7. Pseudonodosaria Boomgaart, 1949 (BE-3-15); 8. Cribrorobulina Thalmann, 1947 (BE-3-47); 9. Lenticulina Lamarck, 1804 (BE-3-20); 10. Globulina d'Orbigny, 1839 (BE-3-50); 11. Robertina d'Orbigny, 1846 (BE-3-45); 12: Globigerina d'Orbigny, 1826, vista ventral, carapaça dextrógira (BE-3-27); 13. Globigerina d'Orbigny, 1826, vista ventral, carapaça levógira (BE-3-28); 14. Globigerinella Cushman, 1927, vista ventral, carapaça levógira (BE-1-34); 15. Globigerinoides Cushman, 1927, vista dorsal, carapaça levógira (BE-3-36); 16. Orbulina d'Orbigny, 1839 (BE-3-35); 17: Bulimina d'Orbigny, 1826 (BE-3-3); 18. Bolivina d'Orbigny, 1839 (BE-3-11); 19. Brizalina Costa, 1856 (BE-3-9); 20. Uvigerina d'Orbigny, 1826 (BE-3-7); 21. Trifarina Cushman, 1923 (BE-3-39); 22. Sphaeroidina d'Orbigny, 1826 (BE-3-46); 23: Cibicidoides Thalmann, 1939, vista dorsal (BE3-43); 24: Planulina d'Orbigny, 1826, vista dorsal (BE-3-21); 25. Nonion de Montfort, 1808 (BE-3-49); 26. Melonis de Montfort, 1808 (BE-2-53); 27. Heterolepa Franzenau, 1884, vista dorsal (BE-3-23); 28. Ammonia Brünnich, 1772, vista dorsal (BE-1-31); 29. Ammonia Brünnich, 1772, vista ventral (BE-1-30); 30. Calcarina d’Orbigny, 1826, vista dorsal (BE-3-24); 31. Elphidium de Montfort, 1808 (BE-1-52). 